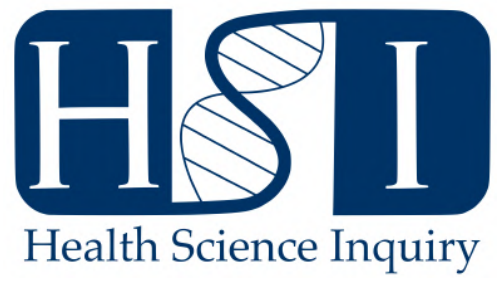

\title{
Armouring the Immune System: Future Prospects of Nanomedicine in Cancer Immunotherapy
}

\author{
Sallie Han $^{1}$ and Dr. John Paul Oliveria ${ }^{2}$ \\ ${ }^{1}$ Department of Medicine, Division of Respirology, McMaster University \\ ${ }^{2}$ School of Medicine, Department of Pathology, Stanford University
}

\section{INTRODUCTION}

Recent advancements in technology has enhanced the targeting ability of drug and molecular delivery systems, opening new doors to improve the current treatments for cancer. Cancer is one of the most deadly and complex diseases with over 18 million new cases reported worldwide in 2018 [2]. In response to pathogens or cancerous cells, the body activates its immunological defense mechanisms to prevent tumour development. However, tumours can escape this immunosurveillance and establish an immunosuppressive environment that downregulates the body's natural defensive response while promoting uncontrolled cancer cell proliferation and tumour growth [3]. Immunotherapy focuses on restoring and enhancing the protective functions of the immune system by stimulating specific immune cells or inhibiting suppressive signals from the tumour cells. This increasingly popular form of therapy include traditional approaches such as tumour vaccines and adoptive transfer, and in the last decade, growing focus have been on antigen presentation through antigen-presenting cells [4]. More recently, some of the safety and efficacy concerns of immunotherapy have been addressed with the application of nanotechnology, which involves the use of small, nano-sized (1-100nm) engineered molecules, termed nanoparticles (NPs), to deliver new or existing therapeutics in a non-toxic and targeted manner [5]. Common forms of nanoparticles include liposomes, polymers, polymeric mi-
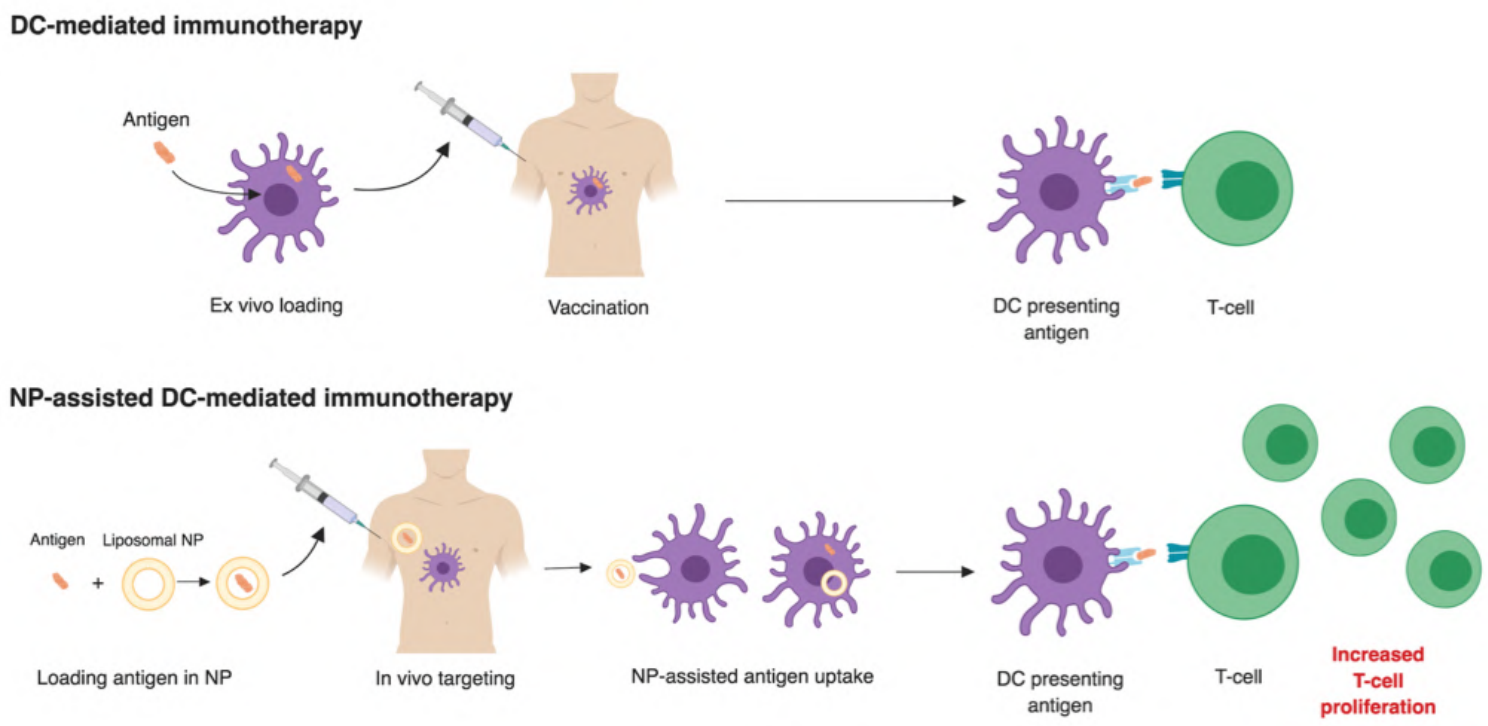

Figure 1: Comparison between DC-mediated immunotherapeutic strategy of ex vivo vaccination in contrast to initial loading of antigen to nanoparticles, such as liposomes, which is subsequently administered in vivo. While both methods lead to enhanced antigen presentation and stimulation of the T-cell immune response in the body, the use of NPs pose pharmacokinetic advantages and greater DC-targeting efficiency, resulting in increased T-cell proliferation [1]. 
celles, and inorganic NPs, each with their own set of unique physical and chemical characteristics [5]. Due to the modifiable properties, improved solubility, and bioavailability of nanoparticles (NPs), nanomedicine can significantly improve the success of immunotherapy by intervening in critical points of the anti-tumour response, such as the antigen recognition and presentation process, as well as checkpoint pathways [5].

\section{The Role of Nanoparticles in DC- MEDIATED IMMUNOTHERAPY}

For initial recognition of the pathogen or cancerous cells in the body, antigen-presenting cells (APCs) such as dendritic cells (DCs) are responsible for phagocytosing the tumour-associated antigen (TAA) and subsequently presenting it to the T-cells to induce the adaptive immune response [6]. One current immunotherapeutic strategy involves vaccinating the patient through stimulating the maturation of the DCs ex vivo with TAA antigens, then transferring the DCs back into the body to increase antigenspecific responses (Figure 1) [1]. However, this method has little evidence of clinical therapeutic effectiveness, unknown longitudinal effects, as well as several cost-associated and technical barriers [1].

NPs provide several advantages as a DC-targeting tool in vivo. NPs can act as carriers that protect the antigens from degradation and prolong the delivery to the DCs. The surfaces can also bind to ligands or have modified physicochemical structures to target receptors found on the DCs [1]. For example, a study published in 2017 found that intravenously administered liposomes carrying TAA-coding RNA was able to efficiently target DCs by adjusting the net charge of the liposome (Figure 1) [1]. Similarly, surface modification can also dictate the antigen uptake, with studies indicating that smaller, hydrophobic, and cationic NPs are correlated with greater internalization and interaction with the DCs [6]. Despite these enhancing functions of the NPs, studies have found impaired antigen-processing ability with NPs like graphene oxide. Other studies have shown varying results of suppression or activation of T-cell differentiation into Th17 cells with different NPs [6]. These findings suggest that the NP's role in DC-mediated immune responses depend on various factors, and require further investigation to understand the full therapeutic potential. Nevertheless, the ability for NPs to improve the detection of pathogens is a promising area of research as it is a critical component to activating the anti-tumour immune response.

\section{The Role of Nanoparticles in Immuno- LOGICAL CHECKPOINT INHIBITION}

Another approach to immunotherapy involves the use of monoclonal antibodies (mAbs) to target immune checkpoints, such as receptors found on immune cells. Such mechanism could block immunosuppression from $T_{\text {reg }}$, improve the anti-tumour immune response, and prevent cancer progression [7]. Examples of widely used mAbs include anti-CTLA-4 and anti-PD-1, also known as Ipilimumab and Nivolumab, respectively [7]. However, there have been several limitations recognized with the use of mAbs alone, such as inadequate pharmacokinetics, limited access to cancerous cells due to the tumour microenvironment, and the need for frequent dosages $[6,7]$. The application of nanotechnology can overcome these limitations by improving the stability of the antibody in vivo, protection from degradation, localising the delivery to the tumour site and reducing the toxic side effects $[8,9]$. A study published in 2011 showed that administering a PD-1 mAb encapsulated in polymer NPs to mice with melanoma resulted in a sustained release of the $\mathrm{mAb}$ and a prolonged anti-tumour response, in comparison to PD-1 mAb alone [10]. Other NPs, such as liposomes, micelles, and metal and non-metal nanomaterials conjugated to different mAbs were also found to overcome several physiological responses, such as avoiding degradation, crossing the blood-brain barrier, and increasing solu-

Table 1: Comparison of immunotherapeutic interventions delivered by nanoparticles

\begin{tabular}{|c|c|c|c|}
\hline $\begin{array}{c}\text { Immunotherapeutic } \\
\text { Intervention }\end{array}$ & Description & $\begin{array}{c}\text { Limitations overcome } \\
\text { by NPs }\end{array}$ & Example \\
\hline $\begin{array}{l}\text { Subunit vaccination, } \\
\text { (Kapadia et al., } 2015 . \\
\text { Journal of Controlled Release) }\end{array}$ & $\begin{array}{l}\text { Stimulating the immune } \\
\text { system by presenting } \\
\text { antigens to the APCs }\end{array}$ & $\begin{array}{l}\text { NPs can target and deliver } \\
\text { cell-membrane-impermeable } \\
\text { antigens or multiple antigens } \\
\text { to the APCs }\end{array}$ & Lipid-calcium-phosphate NPs \\
\hline $\begin{array}{l}\text { Targeting immunosuppressive } \\
\text { cells inthe tumour } \\
\text { microenvironment, } \\
\text { (Kapadia et al., } 2015 . \\
\text { Journal of Controlled Release; } \\
\text { Torres and Alonso, 2015. } \\
\text { Journal Drug Target) }\end{array}$ & $\begin{array}{l}\text { NPs can target receptors } \\
\text { on immunosuppressive } \\
\text { cells }\end{array}$ & $\begin{array}{l}\text { Target immunosuppressive cells } \\
\text { that hinder anti-tumor immunity } \\
\text { through inhibiting } \\
\text { immunosuppressive signalling, } \\
\text { re-education, impaired generation } \\
\text { and/or death }\end{array}$ & $\begin{array}{l}\text { Lipid-encapsulated clodronate } \\
\text { delivered to tumour-associated } \\
\text { macrophages to induce apoptosis }\end{array}$ \\
\hline $\begin{array}{l}\text { Gene delivery, } \\
\text { (Qui et al., 2017. WIREs: } \\
\text { Nanomedicine and } \\
\text { Nanobiotechnology) }\end{array}$ & $\begin{array}{l}\text { Entering T-cells via } \\
\text { NP delivery system } \\
\text { to modify transcription }\end{array}$ & $\begin{array}{l}\text { Increased uptake into } \mathrm{T} \text {-cells to } \\
\text { cause enhanced cell proliferation }\end{array}$ & $\begin{array}{l}\text { Lipid-assisted PEG-PLGA-based } \\
\text { NPs delivering CTLA-4 }\end{array}$ \\
\hline $\begin{array}{l}\text { Cytokine delivery, } \\
\text { (Kapadia et al., } 2015 . \\
\text { Journal of Controlled } \\
\text { Release; Qiu et al., } 2017 . \\
\text { WIREs: Nanomedicine and } \\
\text { Nanobiotechnology) }\end{array}$ & $\begin{array}{l}\text { Delivery of cytokines } \\
\text { (IL- } 2, \mathrm{TNF}-\alpha, \mathrm{IFN}-\gamma) \\
\text { assisted by lipid and } \\
\text { polymer-based NPs to } \\
\text { specific cell types } \\
\text { and tissues }\end{array}$ & $\begin{array}{l}\text { Prevent rapid excretion \& enzymatic } \\
\text { degradation of cytokines }\end{array}$ & Liposomal delivery of TNF- $\alpha$ \\
\hline
\end{tabular}


bility in the blood [10]. These advantages of NPs can allow for a more effective immune checkpoint function and thus an improved immunotherapeutic response.

\section{LIMITATIONS}

Despite the significant advantages of nanomedicine in cancer immunotherapy, specifically in DC-mediated therapy and checkpoint inhibitors, there are several limitations and challenges to address. Since this is a newly emerging field, a lot of the research is still undergoing clinical trials and many studies are done on simplified animal tumour models. Thus, the research cannot be clinically translated in the human body, which has a far more complex pathological environment [7]. Additionally, DCmediated immunotherapies are limited due to costly and time-consuming procedures involved with harvesting DCs for vaccination [1]. Although the use of mAbs as checkpoint inhibitors is advantageous because of their targeting abilities, each combination must be thoroughly and individually characterized for its unique physical and chemical properties to assess potential toxic effects [10]. Regardless of these challenges, the incorporation of nanomedicine into immunotherapy provides a wide range of possibilities for treatment through other mechanisms as well, such as targeting the cells found in the tumour microenvironment, NP-assisted gene delivery, and NP-assisted cytokine delivery (Table 1) [1].

\section{CONCLUSiON}

Nanotechnology has the potential to shift the standards of cancer treatment through the application of nanomedicine in immunotherapy. Whether through the recognition of the antigen or inhibition of checkpoint pathways, NPs can specifically target different stages of the immune response to provide a more effective and personalized treatment. With further research into the pharmacokinetic profiles of NPs, safety and toxicity assessment, and more human in vivo studies, these small molecules will be able to unlock its full potential in different types of treatment to make a significant impact on the future of cancer therapy.

\section{REFERENCES}

[1] Qiu H, Min Y, Rodgers Z, Zhang L, Wang AZ. Nanomedicine approaches to improve cancer immunotherapy. Wiley Interdisciplinary Reviews: Nanomedicine and Nanobiotechnology. 2017;9(5):e1456.

[2] WHO International Agency for Research on Cancer. Latest global cancer data: Cancer burden rises to 18.1 million new cases and 9.6 million cancer deaths in 2018;. Available from: https://www.iarc.fr/wpcontent/uploads/2018/09/pr263_E.pdf.

[3] Mizrahy S, Hazan-Halevy I, Landesman-Milo D, Peer D. Advanced strategies in immune modulation of cancer using lipid-based nanoparticles. Frontiers in immunology. 2017;8:69.

[4] Disis ML. Mechanism of action of immunotherapy. In: Seminars in oncology. vol. 41. Elsevier; 2014. p. S3S13.

[5] Aftab S, Shah A, Nadhman A, Kurbanoglu S, Ozkan SA, Dionysiou DD, et al. Nanomedicine: An effective tool in cancer therapy. International journal of pharmaceutics. 2018;540(1-2):132-149.

[6] Jia J, Zhang Y, Xin Y, Jiang C, Yan B, Zhai S. Interactions Between Nanoparticles and Dendritic Cells: From the Perspective of Cancer Immunotherapy. Frontiers in oncology. 2018;8:404.

[7] Mahjub R, Jatana S, Lee SE, Qin Z, Pauli G, Soleimani $\mathrm{M}$, et al. Recent advances in applying nanotechnologies for cancer immunotherapy. Journal of controlled release. 2018;

[8] Deng H, Zhang Z. The application of nanotechnology in immune checkpoint blockade for cancer treatment. Journal of controlled release. 2018;

[9] Wang C, Ye Y, Hochu GM, Sadeghifar H, Gu Z. Enhanced cancer immunotherapy by microneedle patchassisted delivery of anti-PD1 antibody. Nano letters. 2016;16(4):2334-2340.

[10] Julien DC, Behnke S, Wang G, Murdoch GK, Hill RA. Utilization of monoclonal antibody-targeted nanomaterials in the treatment of cancer. In: MAbs. vol. 3 . Taylor \& Francis; 2011. p. 467-478. 


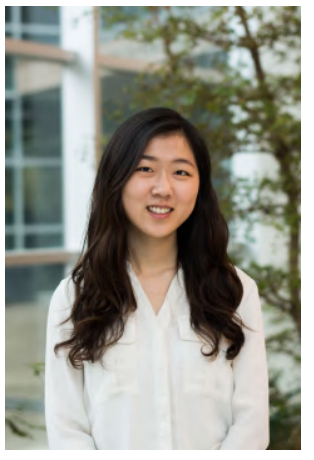

Sallie Han is a 3rd year undergraduate student in the Bachelor of Health Sciences (Honours) program at McMaster University. She is currently working under the supervision of Dr. Oliveria in investigating the cerebrovascular associations in Alzheimer's disease. In addition to her studies, Sallie volunteers as a Clinical Assistant at a cardiology clinic and her research interests include immunology, molecular biology, and vascular pathogenesis.

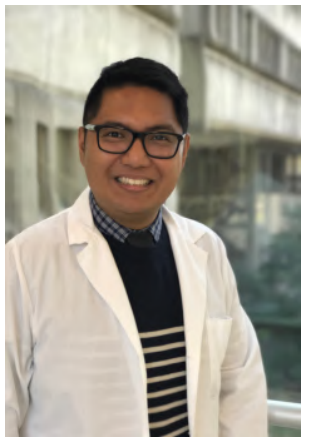

John Paul Oliveria received his PhD in 2017 and is currently an Adjunct Faculty Member at McMaster University in the Faculty of Health Sciences, Department of Medicine, where he supervises students completing projects and theses within the fields of allergy, immunology, and neurosciences. He is currently completing his post-doctoral fellowship at Stanford University where he is utilizing multiplexed ion beam imaging (MIBI) to unravel cellular and sub-cellular interactions in the brain to understand Alzheimer's disease. His research interests leverages novel technologies and high dimensional data to discover novel mechanisms in health and disease. 